\title{
Case Analysis of Farm Agriculture Machinery Informatization Management Network System
}

\author{
Hui Yang*, Xi Wang, and Weidong Zhuang \\ Institute of Engineering, Heilongjiang August First Land Reclamation University, \\ Daqing, 163319, Heilongjiang Province, P.R. China, \\ Tel.: +86-459-6819224; Fax: +86-459-6819210 \\ hicleni@gmail.com
}

\begin{abstract}
In the process of China's agricultural modernization, especially agricultural machinery modernization, in terms of equipment, we've chose the way that foreign imports (and domestic research) with the combination of self-developed, in the software, it is difficult to fully apply this approach, the specific reasons are: the modernization of China's agriculture development model is diversified, it is difficult to find a unified management model, even in the scale of operations of the representative state-owned farms and the abroad farms are also very different management models. Due to various types of growth models of biological complexity, diverse climatic and geographical environment factors, coupled with the characteristics such as long cycle of agricultural production, high input, high-risk, and decentralized management, industrial management mode it is very difficult to apply. Moreover, the application of modern management tools is also difficult to quantify the benefits, leading to the current research and application are in a state of comparatively dropped behind.
\end{abstract}

Combination the development of "Farm agricultural machinery informatization management system in The network integration system of digital agriculture of Heilongjiang province", Heilongjiang August First Land Reclamation University Digital Agriculture Project Team carried out case studies and experiments in a few more advanced farms (Red Star Farms, Seven Stars Farm, etc.) in Heilongjiang Province. In order to facilitate the unified management of the farm machinery operation, the agricultural machinery operation management system was achieved through a form of a web site design. With the support of precision agricultural technique, which include information management, farm machinery job scheduling, agricultural machinery performance standards and the accounting standard of the workload, the supply of fuel and spare parts, maintenance organizations and reminders, statistics analysis of the technical and economic indicators, financial accounting, as well as the necessary network meeting support systems, etc.

To integrate the analysis and design of the informatization management network system of a farm, the efficient path of the farm machinery management modernization of a farm should be researched, in this paper, some details were discussed in the research and constructive foundation of agricultural machinery

${ }^{*}$ Corresponding author. 
management modernization, the roles and actions of farm machinery informatization management network system in agricultural modernization, description of the issue of the farm machinery informatization management network system, the design of internal modular structure, external network system interface, open source questions and the improvement path to follow, etc.

Keywords: agricultural; agricultural machinery; farm machinery; informatization; management modernization; network system; job scheduling; performance standards; maintenance organizations.

\section{Project Background}

In the process of China's agricultural modernization, especially agricultural machinery modernization, in terms of equipment, we've chose the way that foreign imports (and domestic research) with the combination of self-developed, in the software, it is difficult to fully apply this approach, the specific reasons are: the modernization of China's agriculture development model is diversified, it is difficult to find a unified management model, even in the scale of operations of the representative state-owned farms and the abroad farms are also very different management models. Due to various types of growth models of biological complexity, diverse climatic and geographical environment factors, coupled with the characteristics such as long cycle of agricultural production, high input, high-risk, and decentralized management, industrial management mode it is very difficult to apply. Moreover, the application of modern management tools is also difficult to quantify the benefits, leading to the current research and application are in a state of comparatively dropped behind.

Combination the development of "Farm agricultural machinery informatization management system in The network integration system of digital agriculture of Heilongjiang province", Heilongjiang August First Land Reclamation University Digital Agriculture Project Team carried out case studies and experiments in a few more advanced farms (Red Star Farms, Seven Stars Farm, etc.) in Heilongjiang Province.

To integrate the analysis and design of the informatization management network system of a farm, the efficient path of the farm machinery management modernization of a farm should be researched, in this paper, some details were discussed in the research and constructive foundation of agricultural machinery management modernization, the roles and actions of farm machinery informatization management network system in agricultural modernization, description of the issue of the farm machinery informatization management network system, the design of internal modular structure, external network system interface, open source questions and the improvement path to follow, etc.

\section{System Overview and Description of Structure and Function}

In order to facilitate the unified management of the farm machinery operation, the agricultural machinery operation management system was achieved through a form of a 
web site design. With the support of precision agricultural technique, which include information management, farm machinery job scheduling, agricultural machinery performance standards and the accounting standard of the workload, the supply of fuel and spare parts, maintenance organizations and reminders, statistics analysis of the technical and economic indicators, financial accounting, as well as the necessary network meeting support systems, etc.

Discussed below in light of the actual cases.

\subsection{Build Information Management and Publishing Platform}

Broadly speaking, project of farm agricultural machinery informatization management system in the farm agricultural machinery informatization management network system in fact covers the modules shown in Figure 1.

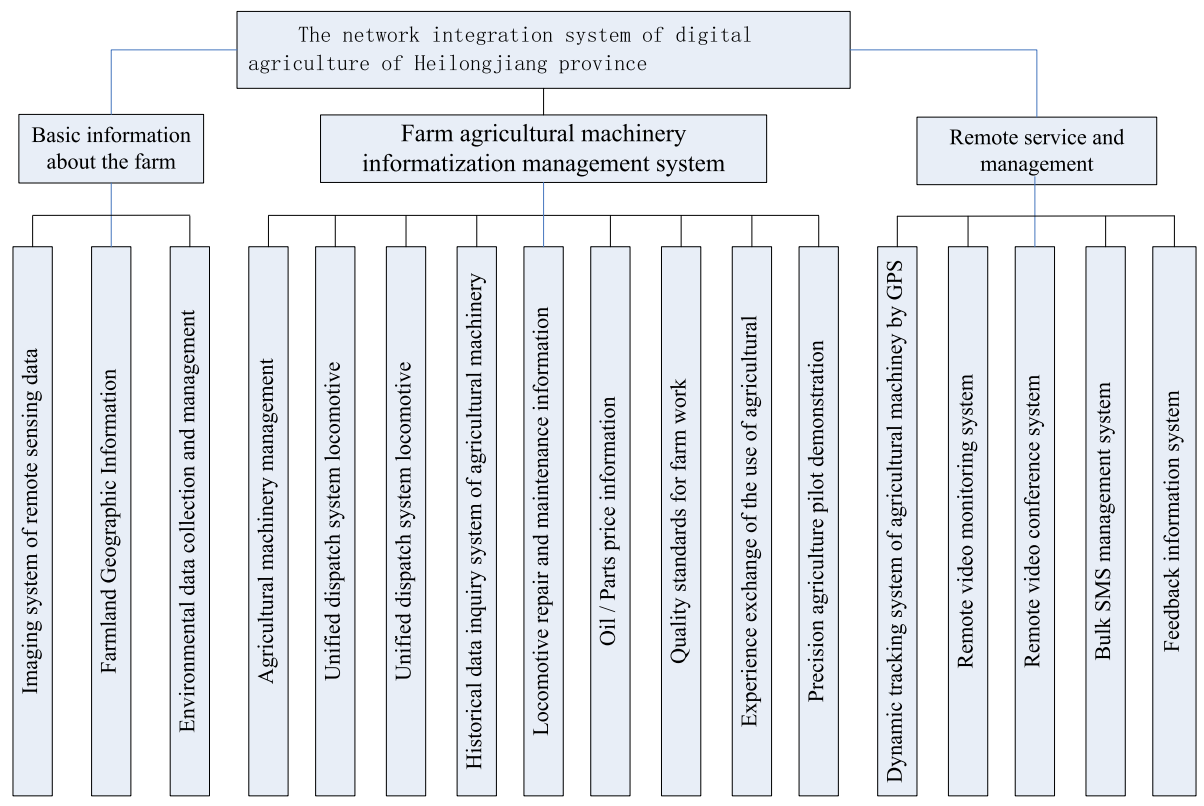

Fig. 1. Farm agricultural machinery Informatization management system HIPO Chart

About web site design we chose the Browser/Server structure, behind the web server, we also need some map engine and some database server for basic information and realtime information, etc.

Network topology diagram of the network integration system of digital agriculture of Heilongjiang province shown in Figure 2. 


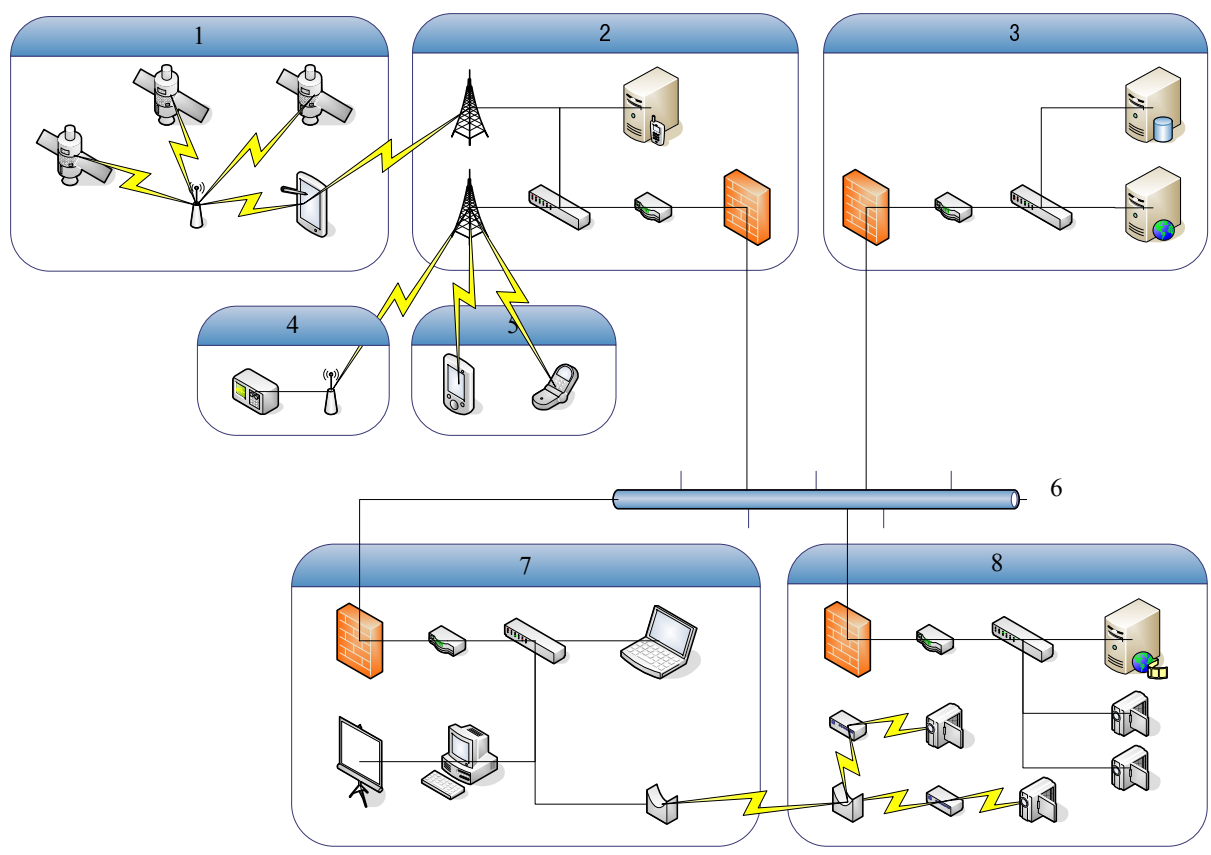

Fig. 2. Network topology diagram of the network integration system of digital agriculture of Heilongjiang province(1)dynamic tracking system of agricultural machiney by GPS; (2)telecom service provider; (3)web server; (4)environmental data collection; (5)bulk SMS management; (6) internet; (7)unified dispatch center; (8)remote video capture

\subsection{Macros Decision Support Providing}

It is an important means to improve the scientific of the agricultural machinery management that enhanced the functions of forecasting, operations and decisions in a agricultural mechanization information management system software, the necessary decision support module is provided by most of the agricultural information management software, a number of conventional or unconventional algorithm model is integrated, serve the purpose of forecasting, operations and decisions support as much as possible. For example, the forecast function in the development of agricultural machinery is achieved by use of least square method, BP neural networks, gray-Markov chain model; the combination forecasting function in the development of agricultural machinery is achieved by use of rough set theory; the decision function in the development of agricultural machinery is achieved by use of operations research model such as AHP(Xinjie Yu, 2004).

The intelligent decision support function modules of soil testing fertilization is included in the system design of "The digitalization of farm agricultural machinery management system in the farm agricultural machinery informatization management network system", it is still under research and development, and match with the historical database of land information of precision agricultural and ancillary equipment 
such as variable rate fertilization device have been entered the implementation phase. The forecast, decision function modules referred above have not been included in this system since the study focused on different purpose.

\subsection{Depth in the Direction of the Core Management Modules Such as the Enterprise Resource Planning and Scheduling Management}

At present, a series of core information management function modules have been get implemented such as the enterprise resource planning and scheduling management, it has been fully applied in industries such as coal, automobiles, hydraulic and electric power, etc. Due to some special reasons, the research and application of the process of agriculture production is lagging behind the general level, we now need to devote more energy to study.

As an example, studies has been done on agricultural machines optimization and allocation and service system construction in Shanghai farm by Jun Shi, the management system played an important role in following aspect: uniform implementation of standardization of technical measures on agricultural operations, uniform management of agriculture equipment, uniform scheduling mechanical operations, uniform maintenance and optimum combination, achieved with minimal input and the lowest cost to maximize machinery operation to meet demand for agricultural production, In order to achieve large-scale agricultural machinery management, agricultural equipment played the economies of scale, implement the standardization of agricultural machinery management, strengthen the total quality management of agricultural production process, to ensure safety in agricultural production with agricultural machinery, etc. but in fact they did not put the negative effects of the planned economy. It is in a matter of ongoing exploration that how to resolve keeping the above-mentioned advantages of the original management system under the premise in both, also contradictory to adapt with the construction of agricultural mechanization service system against the backdrop of market-oriented economy in agriculture. A highly efficient and flexible information technology itself, characterized by open and transparent, make it more suitable for the role of supplying a scientific planned guidance for a low cost of the non-mandatory advice and services for the agricultural market, It retains the advantages of guiding plans, also with a very flexible response capability on the rapidly changing market economy. With the opportunity for a comprehensive science and technology, information technology and biotechnology as the leading process of agricultural modernization. It is not impossible to provide a way out to explore the solutions for these conflicts status quo(Jun Shi, 2006).

The system attempt to cover the agricultural machinery job scheduling, agricultural machinery operations standards and the workload accounting, fuel and spare parts supply, maintenance organizations and reminding, report forms analysis and statistics of the techno-economic indicators, financial accounting and other typical management problems of agricultural machinery management, while it is primary, however, this information on behalf of the further request of the farm management informationize.

A simple working procedure of farm station locomotive work looks like figure 3: 


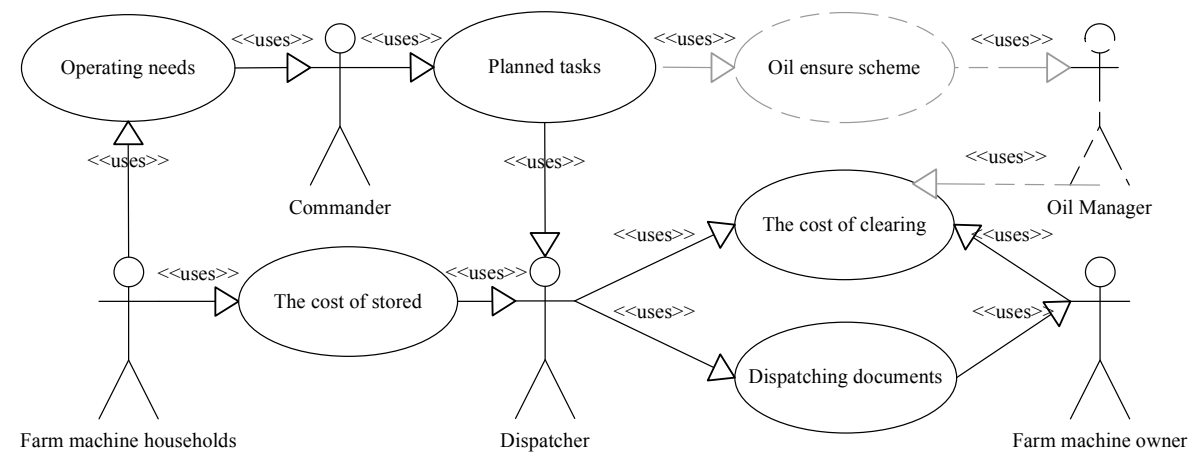

Fig. 3. A simple working procedure use case of farm station locomotive work

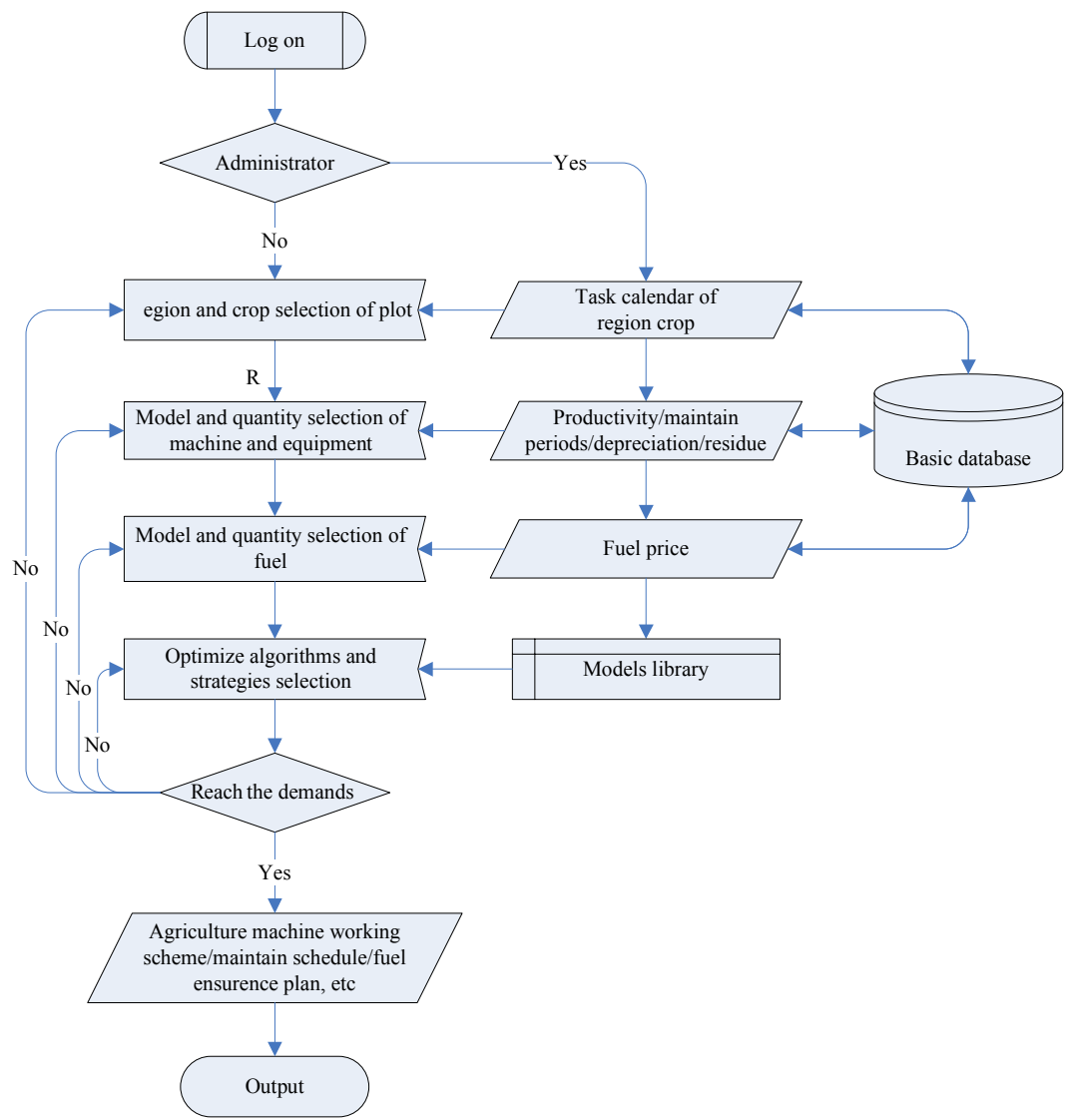

Fig. 4. Agriculture machine job scheduling constitute breviary flow figure 
From the figure 3, the key sector of farm workstation working flow is the constitution and carrying into execution of agriculture machine job scheduling. The scheduling can be divided into long term, middle and short term scheme, and a profile of the agriculture machine job scheduling constitution flow figure looks like figure 4.

\section{Review and Analysis of System Development}

\subsection{Construction Repeats Problem}

This includes the concept overlap with other agricultural information systems, the duplication of software R \& D issues with similar areas of domain, the sharing and cooperating with other relevant public information, and so on.

According to the authors know, farm-level managers have become increasingly aware of the important role of information technology in farm management, However, Specific operation in the process, may be biting off more than for large, aggressive committed errors, sometimes there is an obvious problem of redundant construction. Although the contribution rate of the informatization of agriculture is not very easy to calculate accurate, I suggest that at least the value of the project evaluation should be done by the concerned departments to carry out.

Farms now have a certain autonomy, but also the guide department of the government in charge of the development of farms, duplication should be avoided by coordination between the farm and the government, to break the technical barriers and identify the common domain. To resolve this problem I advocate component-based technology and open source development model (See part 4).

\subsection{Accurate Positioning of the System, Evaluation and Feedback}

Accurate positioning of the system needs to re-examine the meaning of agricultural management, agricultural mechanization management is the general term of the integrated use of management about the main theories, the mind, the ways and the means, the organizations and the systems and so on, on the management of agricultural mechanization, of main body of the management of agricultural mechanization. The traditional management concepts of agricultural mechanization is the management, supply, manufacture, maintenance and repair, scientific research, technical support, training and the use of such work of agricultural machinery, unified management by the agricultural sector of the government. With the development of agricultural mechanization, agricultural mechanization means more detailed management functions, an increase of agricultural technology popularization and application, agricultural machinery safety supervision, identification of agricultural products and quality supervision, identification of vocational skills of skilled workers, agricultural mechanization information and propaganda (Qicai Li, 1999). As well as the penetration is expected in the functions of the general plan, organizational, command, control, coordination, feedback and so on (Xingguo Li, 2006).

General agricultural information management system usually contains most of the information service functions, forecasting, decision support functions and internal 
information management functions, such as conventional modules. To determine the degree of importance and urgency of a system function, we should look at the impact of its economic effectiveness of enterprises or social benefits, for example, early warning of nature factors in agriculture, the process management of agricultural mechanization production and so on.

Mingyan Hu carried the research on demand analysis and resource configuration of the regional manufacturing informatization, and in her paper the efficiency of financial resources and the economic growth rate of informatization is calculated(Mingyan $\mathrm{Hu}$, 2004). Wen Ru carried the research on construction strategy and comprehensive evaluation of China's enterprise informatization, the calculation method of the tangible business benefits and the evaluation method of the intangible benefits of enterprise is talked about(Wen Ru, 2003). A specific analysis for the focus of the project should be carried through the use of these algorithms of quantitative analysis and methods of qualitative analysis for guiding the direction of development to fetch the desired effects.

\section{To Explore the Evolution of System Software}

Combine the understanding of the development and construction of the system mentioned above, if the entire informatization can be divided into two parts: hardware and software, the following text try to talk about some of the details of the whole from the perspective of software evolution.

\subsection{The Development, Reuse and Sharing of Network Components}

According to the software product line concepts and ideas pointed out by scholar $\mathrm{Fu}$ qing Yang (JadeBird engineering put forward the concept during "75" period): the software production process can be divided into components production, framework production, components and framework reusing. Software components / framework technology is the core of software production, organically linked the domain engineering and application engineering through the aspects of component management and re-engineering. Combined with project management, organizational management, such as management issues, form a complete software production process (Fuqing Yang, 1996; Fuqing Yang, 2005).

For such a software role of agricultural information management network system, it is used primarily as an integrated production of application development, it should play the role of components reusing in the software product line. Once the farm want to consider a further upgrade of the system to a deeper level of the enterprise management, the current system is going to be integrated into a larger system as a subsystem, or attempting to take certain level of component for reuse, decomposition of component is to support or face-out, is a very tough choice. Therefore, it is very necessary to consider the picture of the whole, to do a good job at the beginning of the project on the specific historical background and forward-looking long-term planning.

Scholar Fuqing Yang believe that network-oriented computing environment is currently moving from Information Web to Software Web, software componentware 
should be formed as internetware. That is, to adapt to the open and dynamic external networks environment, as well as the users use the personalized request, the adjustment of the static and dynamic evolution should be carried out in accordance with the function, performance indicators, such as the indicator of the credibility, so that the highest possible reliability software patterns for users can be formed.

From the perspective of micro, internet will enable the research focus of the development of system software and supporting platform shifted from the operating system to the new middleware platform, breakthrough in internetware theory, methods and techniques will lead to a breakthrough in establishing a new pieces of innovative technology platform of new type of intermediate. The current software technology follow the law of the combination of software and hardware (microelectronics), the combination of application and systems development. To develop systems and products application-oriented, integration, for personal, reflecting individual. The overall development trends of software technology can be summarized as follows: software platform for network-based, object-based approach, system component, products of family, and the development of engineering, process standardization and production scale, and international competition (Fuqing Yang, 2002).

Based on such a background, the design of farm agriculture machinery informatization management network system should be subjected to the network-based, component-based development path. Decompose the system components for the suitable size, full research argues and give priority to the use of existing component library products. Sharing the good reusable components that are not inconsistent with the premise of the TRIPS Agreement, increasing the flexibility and robustness structures of components by the perspective of a comprehensive plan from the using of design patterns.

(1)Perhaps the existing system can borrow ideas from the integration patterns of the SNS which known as the more popular examples: Widget is used to increase the capacity of cross-domain interaction, as far as possible the original system changes slightly;

(2)A new design can be adopted for the newly developed system, the whole of the components fully taken into account, to use the mature design patterns as far as possible, design reusable components;

\subsection{Try the Applicability of the Open Source Technology System on the Informatization of Agricultural}

In view of the difference of China's agricultural enterprises and the ordinary industrial enterprises or the tertiary industry, to start a number of government-funded open-source projects, I guess, will have a multiplier effect. At present, open source technology system have shown strong vitality to flourish in many areas, the revitalization of the software industry of our nation are also depends on the healthy development of the open-source technology system, I think that might be a good starting point to seek cross-point in the agricultural areas and the open source areas that the demand and the supply both are unique. 
International original open-source resources web site platform such as http://sourceforge.net, http://apache.org/, updating very frequently, domestic http://cosoft.org.cn/ is also a good open source resource site. The GNU organization, Free Software Foundation (FSF), and the various open-source licenses represented by GPL, as well as the wealth products of the platform and a large number of workers, provide a broad space for the development of open-source system. It can be said that all the software in the field of closed source systems are provided corresponding products with the open source side by side, although they are not necessarily the same level, in fact each other high. There is no reason for agricultural information technology to turn a blind eye to these resources, which is a magic weapon for development the software industry by leaps and bounds, which is the only way to break the technical barriers, rapid approach international advanced level and access to the independent intellectual property rights.

I envisaged, we can distribute information technology component or code fragments through open-source license, allowing users to assemble their own open-source product, which will play a powerful role in adding fuel to the flames on cultivating a large number of agriculture technicist familiar with open source products, improve the overall quality of the agriculture technical personnel of grass-roots level, speed up the process of informatization. of course, it is not realistic for the grass-roots level technical personnel to learn to count on the complexity, as the leader, it requires our universities and research institutions to have dedication, to launch open-source team, give their time and energy.

Once the open source components are capable of covering the basic necessary component set of the farm agriculture machinery informatization products, when it is feasible for a agriculture grass-roots level to build their own applications of information technology, open source technology system will certainly be recognized by everyone, then the benefits of it will be multi-faceted, not just the software products directly own low-cost, high efficiency, will also train a large number of technical staff, bring whole Industry a qualitative progress. The great social benefits, reactive in contemporary, benefit future generations.

Limited to the subject matter hereof, on the open-source technology systems, business models are not discussed, it can be said, the resources-related projects and documents, academic papers are voluminous and can not be enumerated one by one (Haifang Chang, 2007; Guangfeng Wang, 2008).

\subsection{A Phased Implementation Strategy}

Hebei Agricultural University, Dr. Zhang Honggang studied on the informatization development strategy of the county economic(Honggang Zhang, 2008), a comprehensive summary of the macro level of the county agricultural development measures is talked about. The development and countermeasures of China's enterprise informatization is talked about by Lili Zhang of Taiyuan University of Technology (Lili Zhang, 2003), in the paper, it referred several correlative aspect, such as, to improve staff quality, it need to be considered people-oriented when determine the construction and implementation strategies of informatization of China's enterprise; planning objectives 
and step by step; emphasis the support of on core business and the core competitiveness; to do a good job in corporate strategic data planning; to avoid the risk of informatization; and combine with the management innovation; focused, at different levels and progressive implementation; to do a good job in the normalization and standardization of enterprise information management; to deal with external parties and corporate relations; to do a good job in the evaluation and inspection, in maintenance and expansion of enterprise informatization; to pay attention to the industry experts, co-operation with the third-party consulting firm, etc.

Accordance with the positioning of system development in part 3.3, in order to achieve optimal distribution and positive roll of informatization resources, it is necessary to carry out a overall planning for informatization process. This is also researched and discussed very much. Concerned about the title in terms of the farm agriculture machinery informatization management, the author advocates the development of an incremental process. Focused on the system, carry a gradual implementation of a hierarchical, step by step into the support level of enterprise core business and core competitiveness, push the evolution down-to-earth from the digitization to the comprehensive informatization, in order to circumvent the risks of informatization, so that the process of informatization can be realy implemented.

\section{References}

Yang, F.Q.: Thinking on the development of software engineering technology. Journal of Software 16(1), 1-7 (2005)

Yang, F.Q.: The present and development of JadeBird engineering-discussion on development approach of national software industry. In: Yang, F.Q., He, X.G. (eds.) Proc. of the 6th National Software Engineering Academic Conf. Tsinghua University Press, Beijing (1996) (in Chinese with English abstract)

Yang, F.Q., Mei, H., Lü, J., Jin, Z.: Some discussion on the development of software technology. Acta Electronica Sinica 30(12A), 1901-1906 (2002) (in Chinese with English abstract)

Chang, H.: The research and implementation of the OSS based administration system of telecom integrated OA, Beijing University of Posts and Telecommunications, Master degree thesis, 3 (2007)

Wang, G.: Competition between open source and proprietary software: research based on the system software market, Liaoning University, Doctoral dissertation, 4 (2008)

Zhang, H.: Research on the Strategies in the Development of the County Economic Informatization. Management Science, Hebei Agricultural University, Doctoral dissertation, 6 (2008)

Zhang, L.: Present situation and countermeasure research of enterprise information of our country, Management Science and Engineering, Taiyuan University of Technology. Master's thesis, 4 (2003)

$\mathrm{Yu}, \mathrm{X}$. : The research on the MIS for agricultural mechanization based on Web GIS, agricultural mechanization engineering, Zhejiang University, Master's thesis, 7 (2004)

Shi, J.: Studies on agricultural machines optimization and allocation and service System construction in Shanghai farm, Cultivation, Yangzhou University, Master's thesis, 10 (2006)

Jia, Y.: Study on agricultural macroscopic decision-making support system based on GIS, Cartography and Geographic Information System, Beijing Forestry University, Master's thesis, vol. 5, p. 21 (2007) 
Li, X.: Environment analysis and study of evaluation index on agricultural mechanization of China, Agricultural Mechanization Engineering, Hebei Agricultural University, Master's thesis, 3 (2006)

Li, Q., Xiao, Y., Zhang, X., Li, R.: Research on management innovation of agricultural mechanization. Journal of Agricultural Mechanization Research 8(3), 23-41 (1999)

$\mathrm{Hu}$, M.: The research on demand analysis and resource configuration of the regional manufacturing informatization, Mechanical design and theory, Tianjin University, Master's thesis, 1 (2004)

$\mathrm{Ru}$, W.: Research on informatization construction strategy and comprehensive evaluation of China's enterprise, Southwest Petroleum Institute, Master's thesis, 4 (2003) 